\title{
DiÁLOGO DA MODA COM A MORTE
}

\section{DIALOGUE BETWEEN FASHION AND DEATH}

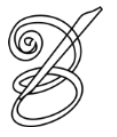 \\ Autor: \\ Giacomo Leopardi \\ Traduzido por: \\ Vinicius HONESKO ${ }^{\mathrm{i} *}$ \\ Universidade Federal do Paraná \\ Curitiba, Paraná, Brasil
}

Resumo: No diálogo, a moda apresenta-se como irmã da morte, falando sobre seus feitos que auxiliariam sua irmã na subjugação dos humanos aos ditames da mortalidade. Depois de um estranhamento inicial por parte da morte, a moda acaba por convencer a morte de que ambas são, de fato, irmãs.

Palavras-chave: Diálogo. Moda. Morte. Irmã. Humanos.

Abstract: In the dialogue, fashion presents itself as a sister of death, talking about her achievements which would assist her sister in subjugating humans to the dictates of mortality. After an initial estrangement from death, fashion ends up convincing death that both are, in fact, sisters.

Keywords: Dialogue. Fashion. Death. Sister. Humans.

RECEBIDO EM: 5 de setembro de 2019

ACEITO EM: 25 de novembro de 2019

PUBLICADO EM: março 2020 


\section{DiÁlOGO DA MODA COM A MORTE}

MODA: Madame Morte, Madame Morte.

MORTE: Espere que seja a hora e virei sem que tu me chames.

MODA: Madame Morte.

MORTE: Vá com o diabo. Virei quando tu não quiseres.

MODA: Como se eu não fosse imortal.

MORTE: Imortal? Mais de mil anos já se passaram desde que os tempos dos imortais terminaram.

MODA: Também a Madame é petrarquista como se fosse um lírico italiano do Quinhentos ou do Oitocentos?

MORTE: Tenho muita estima pelas rimas de Petrarca, pois nelas encontro meu triunfo e por que falam de mim por toda parte. Mas, em suma, estou indo.

MODA: Espere! Pelo amor que tu tens pelos sete vícios capitais, pare um pouco e olhe-me.

MORTE: Olho-te.

196 MODA: Não me conheces?

MORTE: Deverias saber que tenho uma visão ruim e que não posso usar óculos, porque os ingleses não os fazem de modo a servir-me e, ainda que os façam, não teria onde apoiá-los.

MODA: Sou a Moda, tua irmã.

MORTE: Minha irmã?

MODA: Sim, não te lembras de que nós duas nascemos da Caducidade?

MORTE: O que posso recordar se sou inimiga capital da memória?

MODA: Mas eu me lembro bem e sei que tanto tu quanto eu muito nos esforçamos para desfazer e transmutar continuamente as coisas aqui em baixo, ainda que tu andes por um caminho e eu por outro.

MORTE: Caso não fales com teu próprio pensamento ou com alguém que tu tenhas na garganta, levante mais a voz e articule melhor as palavras, pois se continuares a colocar as palavras entre os dentes com essa vozinha de taquara rachada irei compreendê-la só amanhã, já que o ouvido, caso não saibas, serve-me tão mal quanto a vista.

MODA: Ainda que sejas contrária aos bons costumes e que na França não seja habitual falar para ser ouvido, também por que somos irmãs e entre nós podemos não ter tantas formalidades, falarei como tu queres. Digo que a nossa natureza e costume comum está em renovar continuamente o mundo, mas tu desde o princípio te lançaste sobre as pessoas e o sangue; eu me contento no máximo com as barbas, os cabelos, as roupas, os bens domésticos, os palácios 
e coisas afins. É bem verdade que não me faltaram e não me faltam vários jogos comparáveis aos teus, como, por exemplo, agulhar por vezes orelhas, lábios e narizes, e rasgá-los com bugigangas que coloco nos buracos; queimar a carne dos homens com selos quentes que converto em marcas de beleza; deformar a cabeça das crianças com bandagens e outras engenhocas, impondo o hábito de que todos os homens do país tenham que ter a cabeça da mesma forma, como fiz na América e na Ásia; aleijar as pessoas com calçados pequenos; impedi-las de respirar e fazer com que os olhos lhes saltem para entrarem no corpete ajustado; e cem outras coisas desse gênero. E mais, genericamente falando, eu persuado e constranjo todos os senhores a suportar a cada dia mil fadigas e mil desconfortos, com frequência dores e tormentos, e convido alguns a morrer gloriosamente pelo amor que têm por mim. Isso para não falar das dores de cabeça, dos resfriados, dos fluxos de todo tipo, das cotidianas febres terçãs e quartãs que os homens recebem por obedecer-me, consentindo em tremer de frio ou em afogarse de calor de acordo com o que quero, protegendo as costas com lãs e o peito com lona, fazendo qualquer coisa à minha maneira mesmo que seja com danos para eles.

MORTE: Em conclusão, eu acredito que sejas minha irmã e, se quiseres, tenho-a por mais certa que a morte sem que tu tenhas que me provar. Mas, estando assim quieta, eu desmaio; entretanto, se te dá ânimo correr a meu lado, tenhas cuidado para não cair, porque parto em fuga; correndo poderás falar de tuas necessidades; caso contrário, em consideração ao nosso parentesco, prometo-te, quando eu morrer, deixar todas as minhas coisas, e que tenhas um bom ano.

MODA: Se tivéssemos que correr juntas em competição, não sei quem de nós venceria a prova, pois se tu corres, eu o faço melhor do que se estivesse galopando; e se ficas quieta em um só lugar, se desmaias, eu me destruo. Assim, que corramos juntas e, correndo, como tu dizes, falaremos dos nossos casos.

MORTE: Em boa hora. Já que nasceste do corpo de minha mãe, seria conveniente que tu me ajudasses de algum modo a fazer minhas coisas.

MODA: Eu já o fiz, no passado, mais do que pensas. Para começar, eu, que anulo e transtorno continuamente todos os hábitos, jamais permiti que se extinguisse a prática de morrer e, por isso, podes ver que tal uso dura universalmente até hoje, desde o começo do mundo.

MORTE: Grande milagre que não fizeste aquilo que não poderias fazer!

MODA: Como não posso? Tu demonstras não conhecer a potência da moda. 
MORTE: Bem, bem, com relação a isso teremos tempo de discutir quando chegar o costume de não morrer. Mas, enquanto isso, gostaria que tu, como boa irmã, ajudasse-me a obter o contrário de forma mais fácil e rápida do que fiz até agora.

MODA: Já te contei a respeito de algumas obras que muito te beneficiam. Mas não são grandes coisas em relação a estas sobre as quais quero falar agora. Algumas vezes, mais nestes últimos tempos, para favorecer-te, mandei cair em desuso e no esquecimento as fadigas e os exercícios que ajudam no bem-estar corporal, e introduzi ou coloquei em relevância incontáveis usos que recaem sobre o corpo de mil modos e encurtam a vida. Além disso, coloquei no mundo tais ordens e tais costumes que a própria vida, tanto em relação ao corpo como em relação à alma, é mais morta do que viva; tanto que, em verdade, este século pode ser chamado o século da morte. E enquanto antigamente tu não tinhas outras possessões senão covas e cavernas, onde no escuro semeavas ossaturas e poeiras, que são sementes que não dão frutos; agora tens o terreno ao sol e as pessoas que se movem e que andam por aí a pé; são coisas, pode-se dizer, de teu pleno direito, ainda que tu não as tiveste colhido desde que elas nasceram. Ainda mais, se antes eras odiada e insultada, hoje, por minha obra, as coisas se reduziram a termos que quem quer que tenha inteligência te prestigia e louva, antepondo-te à vida, e te quer tão bem que sempre te chama e te dirige os olhos como à sua maior esperança. Finalmente, porque via que muitos tinham a presunção de fazer-se imortais, isto é, de não morrer por completo, pois tinham a ideia de que uma boa parte de si não te cairia nas mãos, eu, sabendo que se tratava de bobagens e que quando estes ou outros vivessem na memória dos homens, viveriam, por assim dizer, de escárnio, sem gozar da sua fama mais do que se sofressem com a umidade da sepultura. De toda forma, compreendendo que esse negócio dos imortais te desagradava, pois parecia diminuir-te a honra e a reputação, acabei com esse hábito que busca a imortalidade, e também com o de concedê-la em caso de alguém que a merecesse. De modo que, no presente, estás segura de que, a quem quer que morra, não lhe resta nem mesmo uma migalha que não esteja morta e que lhe convém ser subitamente enterrada, como um pescado quando é tragado com uma só bocada, com cabeça, espinhas e todo o resto. Essas coisas, que não são poucas nem pequenas, as fiz por amor a ti, querendo engrandecer teu estado na terra, como aconteceu. $\mathrm{E}$ para esse efeito estou disposta a fazer todo dia cada vez mais; com essa intenção é que fui a tua procura, e parece-me apropriado que de agora em diante nós não nos separemos, pois, estando sempre em companhia, poderemos nos consultar ao mesmo tempo de acordo com o caso e tomar melhores decisões do que antes, como também executá-las da melhor maneira.

MORTE: Tu dizes a verdade e assim quero que façamos. 


\section{DiALOGO DELLA MODA E DELLA MORTE}

MODA: Madama Morte, madama Morte.

MORTE: Aspetta che sia l'ora, e verrò senza che tu mi chiami.

MODA: Madama Morte.

MORTE: Vattene col diavolo. Verrò quando tu non vorrai.

MODA: Come se io non fossi immortale.

MORTE: Immortale? Passato è già più che 'Imillesim'anno che sono finiti i tempi degl'immortali.

MODA: Anche Madama petrarcheggia come fosse un lirico italiano del cinque o dell'ottocento?

MORTE: Ho care le rime del Petrarca, perché vi trovo il mio Trionfo, e perché parlano di me quasi da per tutto. Ma in somma levamiti d'attorno.

MODA: Via, per l'amore che tu porti ai sette vizi capitali, fermati tanto o quanto, e guardami.

MORTE: Ti guardo.

MODA: Non mi conosci?

MORTE: Dovresti sapere che ho mala vista, e che non posso usare occhiali, perché gl'Inglesi non ne fanno che mi valgano, e quando ne facessero, io non avrei dove me gl'incavalcassi. MODA: Io sono la Moda, tua sorella.

MORTE: Mia sorella?

MODA: Sì: non ti ricordi che tutte e due siamo nate dalla Caducità?

MORTE: Che m'ho a ricordare io che sono nemica capitale della memoria.

MODA: Ma io me ne ricordo bene; e so che l'una e l'altra tiriamo parimente a disfare e a rimutare di continuo le cose di quaggiù, benché tu vadi a questo effetto per una strada e io per un'altra.

MORTE: In caso che tu non parli col tuo pensiero o con persona che tu abbi dentro alla strozza, alza più la voce e scolpisci meglio le parole; che se mi vai borbottando tra' denti con quella vocina da ragnatelo, io t'intenderò domani, perché l'udito, se non sai, non mi serve meglio che la vista.

MODA: Benché sia contrario alla costumatezza, e in Francia non si usi di parlare per essere uditi, pure perché siamo sorelle, e tra noi possiamo fare senza troppi rispetti, parlerò come tu vuoi. Dico che la nostra natura e usanza comune è di rinnovare continuamente il mondo, ma tu fino da principio ti gittasti alle persone e al sangue; io mi contento per lo più delle barbe, dei 
capelli, degli abiti, delle masserizie, dei palazzi e di cose tali. Ben è vero che io non sono però mancata e non manco di fare parecchi giuochi da paragonare ai tuoi, come verbigrazia sforacchiare quando orecchi, quando labbra e nasi, e stracciarli colle bazzecole che io v'appicco per li fori; abbruciacchiare le carni degli uomini con istampe roventi che io fo che essi v'improntino per bellezza; sformare le teste dei bambini con fasciature e altri ingegni, mettendo per costume che tutti gli uomini del paese abbiano a portare il capo di una figura, come ho fatto in America e in Asia; storpiare la gente colle calzature snelle; chiuderle il fiato e fare che gli occhi le scoppino dalla strettura dei bustini; e cento altre cose di questo andare. Anzi generalmente parlando, io persuado e costringo tutti gli uomini gentili a sopportare ogni giorno mille fatiche e mille disagi, e spesso dolori e strazi, e qualcuno a morire gloriosamente, per l'amore che mi portano. Io non vo' dire nulla dei mali di capo, delle infreddature, delle flussioni di ogni sorta, delle febbri quotidiane, terzane, quartane, che gli uomini si guadagnano per ubbidirmi, consentendo di tremare dal freddo o affogare dal caldo secondo che io voglio, difendersi le spalle coi panni lani e il petto con quei di tela, e fare di ogni cosa a mio modo ancorché sia con loro danno.

200 MORTE: In conclusione io ti credo che mi sii sorella e, se tu vuoi, l'ho per più certo della morte, senza che tu me ne cavi la fede del parrocchiano.' Ma stando così ferma, io svengo; e però, se ti dà l'animo di corrermi allato, fa di non vi crepare, perch'io fuggo assai, e correndo mi potrai dire il tuo bisogno; se no, a contemplazione della parentela, ti prometto, quando io muoia, di lasciarti tutta la mia roba, e rimanti col buon anno.

MODA: Se noi avessimo a correre insieme il palio, non so chi delle due si vincesse la prova, perché se tu corri, io vo meglio che di galoppo; e a stare in un luogo, se tu ne svieni, io me ne struggo. Sicché ripigliamo a correre, e correndo, come tu dici, parleremo dei casi nostri. MORTE: Sia con buon'ora. Dunque poiché tu sei nata dal corpo di mia madre, saria conveniente che tu mi giovassi in qualche modo a fare le mie faccende.

MODA: Io l'ho fatto già per l'addietro più che non pensi. Primieramente io che annullo o stravolgo per lo continuo tutte le altre usanze, non ho mai lasciato smettere in nessun luogo la pratica di morire, e per questo vedi che ella dura universalmente insino a oggi dal principio del mondo.

MORTE: Gran miracolo, che tu non abbi fatto quello che non hai potuto!

MODA: Come non ho potuto? Tu mostri di non conoscere la potenza della moda. 
MORTE: Ben bene: di cotesto saremo a tempo a discorrere quando sarà venuta l'usanza che non si muoia. Ma in questo mezzo io vorrei che tu da buona sorella, m'aiutassi a ottenere il contrario più facilmente e più presto che non ho fatto finora.

MODA: Già ti ho raccontate alcune delle opere mie che ti fanno molto profitto. Ma elle sono baie per comparazione a queste che io ti vo' dire. A poco per volta, ma il più in questi ultimi tempi, io per favorirti ho mandato in disuso e in dimenticanza le fatiche e gli esercizi che giovano al ben essere corporale, e introdottone o recato in pregio innumerabili che abbattono il corpo in mille modi e scorciano la vita. Oltre di questo ho messo nel mondo tali ordini e tali costumi, che la vita stessa, così per rispetto del corpo come dell'animo, e più morta che viva; tanto che questo secolo si può dire con verità che sia proprio il secolo della morte. E quando che anticamente tu non avevi altri poderi che fosse e caverne, dove tu seminavi ossami e polverumi al buio, che sono semenze che non fruttano; adesso hai terreni al sole; e genti che si muovono e che vanno attorno co' loro piedi, sono roba, si può dire, di tua ragione libera, ancorché tu non le abbi mietute, anzi subito che elle nascono. Di più, dove per l'addietro solevi essere odiata e vituperata, oggi per opera mia le cose sono ridotte in termine che chiunque ha intelletto ti pregia e loda, anteponendoti alla vita, e ti vuol tanto bene che sempre ti chiama e ti volge gli occhi come alla sua maggiore speranza. Finalmente perch'io vedeva che molti si erano vantati di volersi fare immortali, cioè non morire interi, perché una buona parte di sé non ti sarebbe capitata sotto le mani, io quantunque sapessi che queste erano ciance, e che quando costoro o altri vivessero nella memoria degli uomini, vivevano, come dire, da burla, e non godevano della loro fama più che si patissero dell'umidità della sepoltura; a ogni modo intendendo che questo negozio degl'immortali ti scottava, perché parea che ti scemasse l'onore e la riputazione, ho levata via quest'usanza di cercare l'immortalità, ed anche di concederla in caso che pure alcuno la meritasse. Di modo che al presente, chiunque si muoia, sta sicura che non ne resta un briciolo che non sia morto, e che gli conviene andare subito sotterra tutto quanto, come un pesciolino che sia trangugiato in un boccone con tutta la testa e le lische. Queste cose, che non sono poche né piccole, io mi trovo aver fatte finora per amor tuo, volendo accrescere il tuo stato nella terra, com'è seguito. E per quest'effetto sono disposta a far ogni giorno altrettanto e più; colla quale intenzione ti sono andata cercando; e mi pare a proposito che noi per l'avanti non ci partiamo dal fianco l'una dell'altra, perché stando sempre in compagnia, potremo consultare insieme secondo i casi, e prendere migliori partiti che altrimenti, come anche mandarli adio esecuzione.

MORTE: Tu dici il vero, e così voglio che facciamo. 


\section{REFERÊNCIA}

LEOPARDI, Giacomo. Dialogo della Moda e della Morte. In.: Operette Morali. Milano: Rizzoli Editore, 1951. p. 29-33.

\footnotetext{
i* Vinicius HONESKO - Bacharel em Direito (2003) pela Universidade Estadual de Londrina. Especialista em Direito do Estado (2005) pela mesma instituição. Mestre em Direito (2007) pela Universidade Federal de Santa Catarina. Doutor em Literatura (2012) pela mesma instituição. Realizou pesquisa de pós-doutorado (2013-2015) na Universidade Estadual de Campinas. Professor Adjunto A na Universidade Federal do Paraná, Setor de Ciências Humanas, Departamento de História. Curitiba, Paraná, Brasil.

Currículo acadêmico: http://lattes.cnpq.br/5914976503033601

ORCID: https://orcid.org/0000-0001-8759-4718

E-mail: viniciushonesko@gmail.com
} 